\title{
Prototipe Palang Pintu Parkir Otomatis dan Informasi Parkir Kendaraan Roda Empat di Pondok Pesantren Nurul Jadid dengan Sensor Infra Red Berbasis Mikrokontroller
}

\author{
Muhammad Fakhrur Rahman ${ }^{1)}$, Sulistiyanto ${ }^{2)}$, Sherly Ferdianto ${ }^{3 \text { ) }}$ \\ Teknik Elektro Fakutas Teknik Universitas Nurul Jadid \\ Karanganyar Paiton Probolinggo \\ Email :Oongamel@gmail.com, sulistiyanto@ymail.com
}

\begin{abstract}
ABSTRAK, Tempat parkir dan sistem pengaturan perparkiran adalah komponen penting dan tidak dapat dipisahkan dalam pelayanan sebuah fasilitas umum. Keberadaan sistem perparkiran yang baik akan mendukung fasilitas umum yang digunakan oleh banyak pihak. Keamanan, kemudahan dan kenyamanan adalah faktor yang diharapkan oleh pengguna fasilitas umum. Oleh karena itu jika sistem perparkiran tidak memberikan keamanan, kemudahan dan kenyamanan bagi pengguna fasilitas umum, maka aktifitas dalam fasilitas umum tersebut akan terganggu. Salah satu fasilitas umum yang masih menggunakan metode perparkiran konvensional adalah area parkir kendaraan roda empat yang berada di Pondok Pesantren Nurul Jadid. Sistem parkir yang bisa dikatakan masih belum terkelola dengan baik, baik dari segi kemudahan dan kenyamanannya terutama untuk para tamu pengunjung (wali santri). Oleh karena itu perlu adanya sistem parkir yang baru, yang dapat bekerja secara otomastis dan tanpa campur tangan manusia.
\end{abstract}

Berdasarkan hasil pengujian alat yang dilakukan, dimana ketika ada mobil yang akan melakukan parkir, maka secara otomatis sensor Infra red yang berada pada palang pintu akan mengirimkan data kepada mikrokontroller, dimana mikrokontroller akan memeriksa, apakah masih ada tempat parkir yang tersedia sesuai dengan data yang dikirimkan sensor Infra red yang ditanam pada setiap slot - slot parkir. Jika masih ada tempat parkir yang tersedia, maka mikrokontroller akan memerintahkan motor servo untuk buka palang pintu dan jika area parkir sudah penuh, maka palang pintu akan tutup. Dan semua informasi akan ditampilkan di LCD. Sistem parkir ini dirancang menggunakan program aplikasi Arduino IDE.

Kata Kunci : Sistem Parkir Otomatis, Infra Red, Arduino IDE, Mikrokontroller.

\section{PENDAHULUAN \\ 1.1 Latar Belakang Masalah}

Tempat parkir dan sistem pengaturan perparkiran adalah komponen penting dan tidak dapat dipisahkan dalam pelayanan sebuah fasilitas umum. Keberadaan sistem perparkiran yang baik akan mendukung fasilitas umum yang digunakan oleh banyak pihak. Sistem parkir yang baik mencerminkan kebaikan sistem yang lebih luas dalam fasilitas umum tersebut. Keamanan, kemudahan dan kenyamanan adalah faktor yang diharapkan oleh pengguna fasilitas umum.
Oleh karena itu jika sistem perparkiran tidak memberikan keamanan, kemudahan dan kenyamanan bagi pengguna fasilitas umum, maka aktifitas dalam fasilitas umum tersebut akan terganggu. Pemilihan metode pelayanan yang baik pada sistem perparkiran akan menentukan keamanan, kemudahan dan kenyamanan fasilitas umum tersebut.

Salah satu fasilitas umum yang masih menggunakan metode perparkiran konvensional adalah area parkir kendaraan roda empat yang berada di Pondok Pesantren Nurul Jadid. Sistem parkir yang bisa dikatakan masih belum terkelola dengan baik, baik dari segi kemudahan dan kenyamanannya terutama untuk para tamu pengunjung (wali santri). Hal ini disebabkan karena tidak adanya petugas parkir yang mengatur area parkir kendaraan roda empat tersebut, sehingga mengakibatkan kesulitan ketika akan ada mobil yang masuk dan yang akan keluar karena cenderung penataannya yang bisa dibilang belum tertata dengan baik. Kemudian luas dari area parkir juga perlu diperhitungkan untuk lebih mengetahui kapasitas maksimal dari area parkir tersebut.

Melihat hal semacam ini maka pada jam sibuk akan terjadi penumpukan antrian yang panjang. Contoh kecilnya ketika hari- hari besar pesantren dimana pada hari itu banyak tamu pengunjung (wali santri) yang berkunjung, terutama yang menggunakan kendaraan roda empat. Lamanya antrian dan lalu lalang kendaraan yang akan melakukan parkir dan keluar dari area parkir mengakibatkan situasi yang kurang kondusif. Area parkir yang juga masih tergolong belum dipetakan, sehingga sering terjadi kekurangan area parkir yang kosong, maka dari itu perhitungan terhadap luas area parkir juga perlu diperhitungkan.

Dari latar belakang diatas, penulis ingin merancang sebuah model perpakiran yang baru, yakni dengan merancang "Prototipe Palang pintu parkir otomatis dan informasi parkir kendaraan roda empat di pondok pesantren nurul jadid dengan sensor infra red berbasis mikrokontroller". Sehingga nantinya area parkir di Pondok Pesantren Nurul Jadid dapat beroperasi secara maksimal. 
JEECOM, Vol. 1, No. 1, Oktober 2019

\section{$1.2 \quad$ Rumusan Masalah}

Berdasarkan latar belakang dan identifikasi masalah

di

ISSN: 2715-0410 


\subsection{Metode penelitian}

atas, dapat diambil rumusan masalah yakni:

1. Bagaimana merancang sistem parkir otomatis menggunakan sensor Infra red berbasis Mikrokontroller yang mampu menampilkan hasil deteksi berupa informasi jumlah dan posisi slot parkir yang kosong pada LCD ?

2. Bagaimana merancang sistem parkir yang bisa membantu memudahkan petugas parkir dan juga pengunjung atau tamu?

\subsection{Batasan Masalah} adalah

Adapun batasan - batasan masalah dari penelitian ini

1. Penelitian dilakukan hingga tahap pengembangan sistem yang terintegrasi berupa prototipe.

2. Pengguna kendaraan yang dapat mengakses palang pintu otomatis ini adalah kendaraan

3. roda empat khususnya tamu - tamu atau pengunjung Pondok Pesantren Nurul Jadid.

4. Perancangan prototipe ini menggunakan Sensor Infra red, dengan berbasis Mikrokontroller ATmega 328, dan hanya untuk kendaraan roda empat.

\subsection{Manfaat Penelitian}

Manfaat yang ingin dicapai jika penelitian ini diimplementasikan antara lain:

a. Kenyamanan bagi pengguna:

- Pengguna tetap didalam kendaraan tanpa perlu membuka jendela sehingga tetap nyaman.

- Kendaraan tidak perlu berhenti terlalu lama sehingga meningkatkan arus lalu lintas di waktu sibuk.

b. Kemudahan dan efisiensi bagi instansi:

- Peningkatan pelayanan yang lebih baik kepada pengunjung khususnya wali santri dan tamu.

- Informasi area parkir tersedia di pintu masuk termasuk kapasitas area parkir dan juga area parkir yang masih tersedia.

- Kendali akses yang lebih nyaman.

\subsection{Tujuan Penelitian}

Berdasarkan rumusan masalah diatas, maka tujuan dari penelitian ini adalah

1. Merancang sistem parkir baru untuk kendaraan roda empat di area parkir Pondok Pesantren Nurul Jadid.

2. Mengembangkan program aplikasi yang dapat diintegrasikan dengan teknologi Mikrokontroller.

\section{METODE PENELITIAN}

Dalam penelitian ini, metode yang digunakan adalah pengumpulan data kualitatif yaitu meliputi wawancara dan observasi, agar penelitian dapat dilakukan sesuai dari pengamatan semua objek yang diteliti serta mengungkapkan semua fakta yang ada pada saat penelitian berlangsung mengenai Prototipe pintu parkir otomatis dan informasi parkir kendaraan roda empat dengan sensor infra red berbasis mikrokontroller. Metode penelitian yang di gunakan dalam penelitian ini adalah Research and Development (R\&D).

Research and Development (R\&D) atau Metode Penelitian dan Pengembangan ialah metode penelitian yang digunakan untuk

menghasilkan alat tertentu serta pengujian keefektifan alat yang di teliti. Untuk dapat menghasilkan alat yang di inginkan digunakan penelitian yang bersifat analisis kebutuhan dan pengujian keefektifan alat tersebut supaya dapat berfungsi dan berguna dimasyarakat, Research and Development (R\&D) telah banyak digunakan pada bidangbidang Ilmu Alam dan Teknik. Hampir semua produk teknologi seperti alat-alat elektronik, kendaraan bermotor, pesawat terbang, kapal laut, senjata, obat-obatan, alat-alat kedokteran, bangunan gedung bertingkat, serta alat-alat rumah tangga modern yang dikembangkan melalui penelitian dan pengembangan. Namun demikian Research and Development (R\&D) bisa juga digunakan dalam bidang ilmu-ilmu social seperti psikologi, sosiologi, pendidikan, manajemen, dan lain-lain. (Shilvia 2012).

\subsection{Alat dan Bahan Penelitian}

Didalam pelaksanaan penelitian yang akan dilakukan ini adalah membutuhkan alat dan bahan, dimana alat dan bahan tersebut sangat di butuhkan dan sangat penting yang harus di perhatikan setiap melakukan suatu penelitian. Berikut adalah alat dan bahan yang di gunakan dalam penelitian.

Alat yang digunakan dalam penelitian ini adalah perangkat keras (hardware) dan perangkat lunak (software) komputer

Perangkat keras yang di gunakan adalah:

1. Unit Laptop

2. Mikrokontroler Arduino

3. Sensor Infra red

4. LCD $16 \times 2$

5. Motor Servo

6. Kabel jumper famale to male, male to male dan famale to famale

7. Project board

8. Dan alat-alat pendukung dalam pembuatan alat

Sedangkan perangkat lunak (software) yang di gunakan 
dalam penelitian ini adalah Arduino IDE sebagai Software pengontrol Mikrokontroler Arduino Uno yang di gunakan sebagai kontrol dalam pembuatan alat ini.

\subsection{Desain (Design)}

Setelah menganalisa permasalahan yang ada pada area parkir kendaraan roda empat PP. Nurul Jadid, selanjutnya digunakan perancangan sistem dengan menggunakan Bagan Alir Sistem (sistem flowchart) yang menunjukkan arus pekerjaan secara keseluruhan dari sistem, selanjutnya Data Flow Diagram yang digunakan untuk alur system yang menunjukkan arus pekerjaan secara keseluruhan dari sistem, yang selanjutnya akan di implementasikan dalam pembuatan koding pada program arduino sebagai pengontrol kerja alat yang nantinya digunakan.

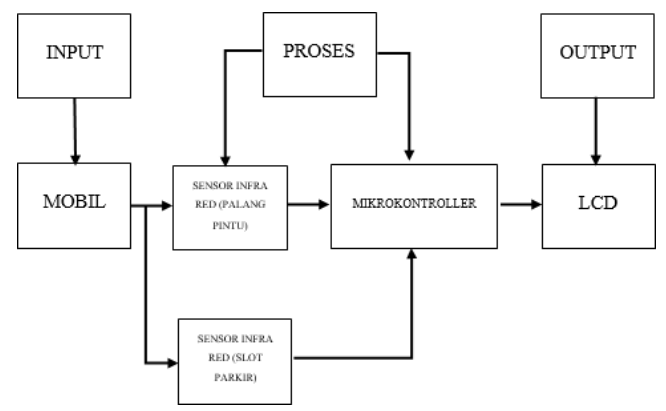

Keterangan Bagan alur sistem diatas :

a. Mobil

Adanya mobil sebagai objek yang akan diteliti

b. Sensor Infra Red (palang pintu) Sebagai sensor

ketika mobil masukatau keluar dari area parkir

c. Sesor Infra red (slot parkir)

Sebagai sensor mobil yang sedang di dalam area parkir

d. Mikrokontroller

Merupakan rangkaian sistem mikrokontroller arduino yang berfungsi untuk menyimpan data di memori dan memproses data.

e. LCD

Untuk menampilkan data dari mikrokontroller.

\subsection{Uji Coba Awal}

Pengujian di lakukan di dalam ruangan tertutup dengan melihat fungsi dari bagian komponen-komponen penting yang di gunakan.

1) Mikrokontroller

Memprogram mikrokontroller untuk memerintahkan semua komponen input/output yang terhubung seperti Sensor, servo dan juga LCD dengan melakukan program kode (coding).

2) Sensor Infra red Mendekatkan tangan di depan sensor dengan berbagai jarak dan di lakukan berulang.
3) Servo

Menjalankan segmen program kode standart untuk membuka dan menutup palang pintu (running servo) dan dilakukan berulang.

4) LCD

Menjalankan segmen program kode standart untuk menampilkan karakter tulisan pada LCD 16x2 dengan karakter tulisan yang berbeda.

\subsection{Uji Coba Akhir}

Pengujian ini di lakukan pada tempat yang sesungguhnya, karena sifat dari penelitian ini adalah prototipe, maka dibuat gambaran kecil (miniatur) yang mendekati pada yang tempat sesungguhnya. Dilakukan di sebuah tempat dengan uji coba yang tidak sesungguhnya melainkan hanya eksperimen dengan situasi sesungguhnya, dan di lakukan berkali-kali agar dapat melihat kekurangan yang akan di perbaiki atau di revisi selanjutnya.

\subsection{Uji Kelayakan}

Pengujian kelayakan ini dilakukan dengan melihat kualitas dan kuantitas yang telah

\subsection{Hasil Pengumpulan Data}

Adapun hasil pengumpulan data yang diperoleh dari hasil observasi dan juga wawancara yang peneliti adakan langsung di Area parkir kendaraan roda empat Pondok Pesantren Nurul Jadid bersama Bagian Penataan Parkir, yakni sebagai berikut.

\subsection{Hasil Observasi}

Penelitian ini mengadakan observasi langsung di Area parkir kendaraan roda empat Pondok Pesantren Nurul Jadid sebagai contoh sistem parkir kendaraan roda empat yang di tangani oleh bagian penataan parkir roda empat yang sebelumnya telah mengadakan proses perjanjian pada tanggal 15 Maret 2019. Observasi di lakukan pada tanggal 30 Maret 2019 sampai 12 Mei 2019 terkait sistem parkir kendaraan roda empat.

Hasil observasi pada Area parkir kendaraan roda empat Pondok Pesantren Nurul Jadid ialah bahwa sistem parkir kendaraan roda empat masih menggunakan cara manual, dimana ketika ada tamu atau pengunjung yang akan melakukan parkir tinggal memarkirkan kendaraan roda empatnya sesuai keinginannya. Hal ini yang menyebabkan kesulitan ketika ada kendaraan lain yang akan melakukan parkir atau keluar dari area parkir, dan lagi ketersediaan tempat semakin minim diakibatkan karena kendaraan roda empat yang parkir tidak tertata dengan baik.

\subsection{Hasil Wawancara}

Pengumpulan data informasi di dapat dengan cara wawancara dengan Bagian penataan parkir kendaraan roda empat Pondok Pesantren Nurul Jadid oleh Bapak Fir Salim, 
S.Sos Wawancara ini di laksanakan pada hari Senin 8 April 2019 tentang sistem parkir kendaraan roda empat di area parkir Pondok Pesantren Nurul Jadid.

Adapun hasil dari wawancara yang di lakukan pada bagian penataan parkir ialah sebagai berikut:

a Sistem parkir saat ini masih terbilang manual, terdapat banyak kendala terkait proses parkir, terutama di waktu - waktu tertentu, semisal ketika kegiatan peringatan hari - hari besar pesantren, istighosah akbar, dan juga kegiatan - kegiatan lainnya. Kurangnya petugas parkir yang mengatur parkir mengakibatkan banyak tamu yang memarkirkan kendaraan secara asal, disempurnakan, sehingga nanti jika memang benar - benar diterapkan akan mendapatkan hasil yang maksimal. sehingga kapasitas area parkir tidak maksimal.

b. Langkah yang ingin dilakukan untuk kedepannya adalah dengan merancang sistem parkir baru, salah satu contohnya dengan merancang sistem parkir otomatis, sehingga tidak terlalu membutuhkan banyak campur tangan dari manusia. Juga dengan memetakan area parkir yang adauntuk saat ini untuk mengetahui kapasitas area parkir yang nantinya akan dijadikan informasi parkir.

c. Dengan adanya sistem parkir yang baru nantinya, diharapkan dapat kembali menngoptimalkan fungsi area parkir tersebut.

Dari hasil Observasi dan wawancara diatas, maka di butuhkan 2 hal penting, pertama analisis sistem parkir lama dan yang kedua analisis sistem parkir yang baru yang akan di bangun.

\subsection{Analisis Sistem Lama}

Menganalisa sistem parkir yang lama merupakan tahapan paling awal dari pengembangan sistem agar sistem yang baru tidak rancu dan saling mendukung serta melengkapi dari sistem yang lama. Berdasarkan hasil observasi dan wawancara bahwa sistem parkir di area parkir kendaraan roda empat PP. Nurul Jadid masih menggunakan sistem manual atau dengan tenaga manusia (petugas parkir).

Berikut identifikasi masalah pada sistem parkir kendaraan roda empat di PP. Nurul Jadid:

a Belum adanya pemetaan dan penataan pada area parkir tersebut, sehingga sering terjadi penumpukan kendaraan roda empat di ruas jalan.

b. Minimnya jumlah petugas parkir yang mengawal kendaraan untuk masuk atau keluar dari area parkir tersebut, sehingga sering terjadi kesulitan kepada pengendara untuk melakukan parkir ataupun keluar dari area parkir tersebut.

\subsection{Analisis Sistem Baru}

Prototipe palang pintu dan informasi parkir otomatis ini di buat untuk memberikan kenyamanan dan kemudahan kepada setiap tamu pengunjung yang akan memarkirkan kendaraan roda empatnya. Memberikan kemudahan dan efisiensi kepada instansi (Bagian Penataan Parkir) Nurul Jadid yaitu :

a. Alat yang bekerja secara otomatis membuka dan menutup palang pintu ketika akan ada kendaraan roda empat yang akan melakukan parkir atau keluar dari area parkir.

b. Alat yang berupa tempat prototipe palang pintu parkir dan informasi parkir otomatis menggunakan sensor Infra red sebagai pemberi sinyal kepada mikrokontroller, kemudian nantinya akan menggerakkan motor servo untuk membuka dan menutup pintu palang, memberi informasi slot yang masih tersedia, kemudian menampilan informasi pada LCD.

\subsection{Pengujian Akhir}

Pengujian Prototipe Palang Pintu Parkir Otomatis Dan Informasi Parkir Roda Empat Berbasis Mikrokontroler Di Pondok Pesantren Nurul Jadid dilakukan untuk mengetahui apakah alat yang di bangun ini dapat memaksimalkan rancangan sistem yang dilakukan sebelumnya. Adapun pengujian yang dilakukan yaitu menguji komponenkomponen yang digunakan pada prototipe tersebut, yang ditunjukkan pada Tabel Hasil Uji Coba prototipe kepada pihak Penataan parkir Pondok Pesantren Nurul Jadid

\section{PENUTUP}

\subsection{Kesimpulan}

Berdasarkan hasil penelitian yang telah dilakukan dapat diambil kesimpulan bahwa:

1. Prototipe palang pintu parkir otomatis dan informasi parkir kendaraan roda empat ini adalah suatu rancangan yang dibuat untuk memudahkan para pengunjung untuk melakukan parkir, dan juga membantu petugas parkir untuk memaksimalkan area parkir yang ada, sehingga area parkir tersebut dapat beroperasi secara maksimal.

2. Prototipe palang pintu parkir ini bekerja ketika ada mobil yang akan melakukan parkir dan mendekat pada sensor Infra red yang ada pada pintu masuk, yang kemudian sensor tersebut akan mengirimkan sinyal kepada mikrokontroller. Mikrokontroller akan memerintahkan Servo 1 (pintu masuk) untuk membuka, kemudian akan tertutup secara otomatis ketika mobil masuk dan menjauh dari sensor. Ketika sampai pada area parkir, mobil akan memilih akan melakukan parkir pada slot 1 atau slot 2, dimana pada masing - masing slot sudah tertera sensor infra red, yang tugasnya adalah memberikan sinyal kepada 
JEECOM, Vol. 1, No. 1, Oktober 2019

mikrokontroller bahwa ada mobil parkir atau tidak pada slotnya. Kemudian untuk alur keluar yakni sensor infra red pada pintu keluar akan

\begin{tabular}{|c|c|}
\hline Wire type & $\begin{array}{l}\text { DC } 4 \text { Wires Type (Brown, Black, } \\
\text { Blue, White) }\end{array}$ \\
\hline Theory & $\begin{array}{l}\text { Photoelectric sensor } \\
\text { retroreflektive type }\end{array}$ \\
\hline Ouput type & $\begin{array}{l}P N P N O+N C \text { (Normally open and } \\
\text { normally close) }\end{array}$ \\
\hline Diameter of head & $18 \mathrm{~mm}$ \\
\hline Detecting distance & $2 m$ \\
\hline Detecting object & Metal, non metal \\
\hline Sup: Part number & \begin{tabular}{l|l} 
& USAFED-20FB2
\end{tabular} \\
\hline Cur Mfg name & Yaskawa Electric \\
\hline Res: Rated output & $1.8 \mathrm{~kW}$ \\
\hline Ext Rated speed & $1500 \mathrm{rpm}$ \\
\hline Rated torque & $117 \mathrm{Kg} . \mathrm{cm}$ \\
\hline Shipping weight & $69 \mathrm{lb}$ \\
\hline
\end{tabular}

mengirimkan sinyal pada mikrokontroller, dan akan memerintahkan untuk membuka servo 2 (pintu keluar), dan akan menutup secara otomatis ketika mobil keluar dan menjauh dari sensor. Ketika area parkir penuh, maka secara otomatis servo 1 (pintu masuk) secara otomatis akan menutup, sampai ada mobil yang keluar dari area parkir. Semua aktifitas diatas akan ditampilkan pada LCD sebagai papan informasi.

\subsection{Saran}

Karena penelitian ini hanya bersifat Purwarupa (Prototipe), Penulis menyarankan jika nantinya ada pihak yang berminat untuk untuk mengembangkan prototipe ini dapat mengganti beberapa perangkat keras yang digunakan, antara lain sebagai berikut :

1. Mengganti Sensor Infra Red pada penelitian ini kepada sensor berkelas industri, salah satunya seperti yang penulis sarankan dibawah ini :

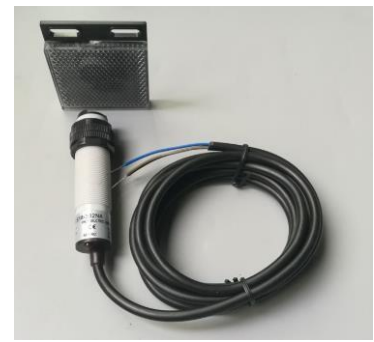
berikut :

Adapun spesifikasi dari sensor diatas adalah sebagai

Tabel Spesifikasi Sensor M18 PNP Infra Red Photocell (Sumber:AlieExpress)

2. Mengganti Motor Servo, pada penelitian ini, motor servo yang digunakan hanya ber-torsi kecil yakni 1,6 $\mathrm{Kg} / \mathrm{cm}$, sehingga jika diaplikasikan pada tempat yang sesungguhnya harus diganti dengan servo yang torsinya lebih besar. Salah satu saran dari penulis yakni sebagai berikut :

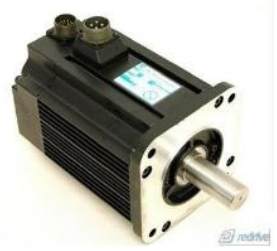

Adapun spesifikasi dari servo diatas adalah sebagai berikut : Tabel Spesifikasi Servo M-fitec FS6530M (Sumber : redrive.com)

3. Karena Area parkir berada pada area terbuka, maka sensor Infrared pada setiap slot parkir harus dipindah, yakni berada di depan mobil. Jika sensor diletakkan di bawah khawatir akan mudah terjadi kerusakan yang diakibatkan oleh air atau benda cair lain ketika musim hujan. Dan juga dikhawatirkan terlindas ban kendaraan ketika akan parkir atau keluar dari area parkir.

\section{DAFTAR PUSTAKA}

[1] Noviyanto, Edi. 2008, Modul Praktek Mikrokontroler ATMega8535, Yogyakarta: Fakultas Sains dan Teknologi UIN Sunan Kalijaga.

[2] Supriatna, Dadang. 2008, Sensor, diakses dari http://elektronikadasar.blogspot.com /2008/04/ sensor.html, pada tanggal 20 Mei 2019.

[3] Syaryadhi, Moch. dkk, 2007, Sistem Kendali Keran Wudhuk Menggunakan Sensor PIR Berbasis Mikrokontroler AT89C2051, Laboratorium Elektronika Teknik Elektro Universitas Syiah Kuala: Jurnal Rekayasa Elektrika Volume 6 No. 1 Tahun 2007.

[4] Wardhana, Lingga. 2006, Belajar Sendiri Mikrokontroler AVR Seri ATMega8535 Simulasi, Hardware, dan Aplikasi, Yogyakarta: Penerbit Andi.

[5] Mc. Leod, R. 2008. Sistem Informasi, Jakarta: Salemba Empat.

[6] Iswahyudi. 2017, Purwapura sistem parkir cerdas berbasis arduino sebagai upaya mewujudkan smart city, home volume 1 No 1 Tahun 2017. 
JEECOM, Vol. 1, No. 1, Oktober 2019

[7] AA Tanjung. 2015, Prototipe Sistem Parkir Otomatis Menggunaan Rfid dan Informasi Area Parkir Melalui Pc Berbasis Atmega8535, Repositori Institusi

Universitas Sumatera Utara (USU-IR) Tahun 2015. 